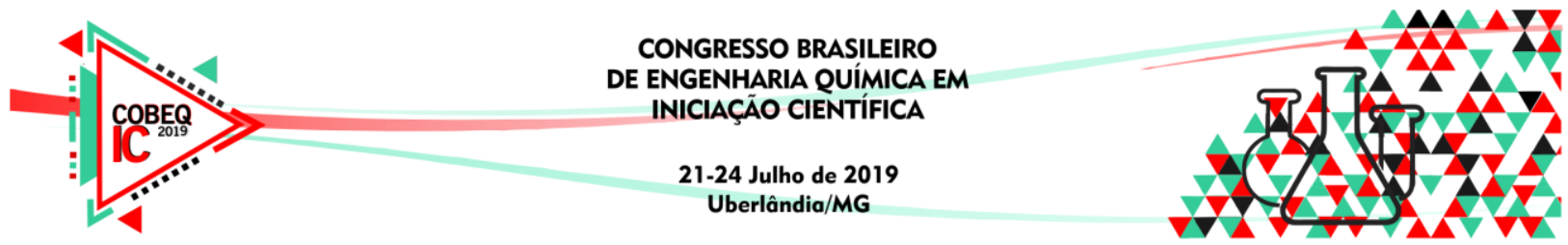

\title{
AVALIAÇÃO DA PRODUÇÃO DE CERVEJA TIPO LAGER EM REGIME SEMICONTÍNUO
}

\author{
A. H. M. LÉLIO e P. MARTA \\ Faculdade Senai Cetiqt \\ E-mail para contato: leliohall@hotmail.com
}

\begin{abstract}
RESUMO - A cerveja é uma bebida carbonatada de baixo teor alcoólico preparada a partir da fermentação do mosto de cevada pela espécie Saccharomyces Cerevisiae, contendo lúpulo e água, podendo ser utilizado outros cereais fonte de carboidratos como arroz, trigo, milho, aveia e centeio. A bebida chegou ao Brasil em 1808 com a família real portuguesa e atualmente o país é o terceiro maior produtor de cerveja do mundo com uma produção anual de 104 milhões de hectolitros. Há 610 cervejarias registradas e em 2017, foram abertos 91 novos empreendimentos no ramo de cervejarias. Dentre as diversas formas de se conduzir a fermentação, tanto para produção de cerveja quanto de outros alimentos fermentados, a mais utilizada é a batelada tradicional ou descontínua. Esta forma de conduzir a fermentação pode acarretar uma baixa produtividade e perda de rendimento, uma vez que o substrato, em excesso no momento da inoculação do microrganismo, exerce efeitos de inibição e repressão catabólica, além de poder desviar o metabolismo celular a produtos que não são de interesse. Com possibilidade de aumentar o rendimento na produção de cerveja, este trabalho teve como finalidade, avaliar a produtividade alcoólica do processo semicontínuo na fabricação de cerveja do tipo lager. A primeira parte do trabalho foi o preparo do mosto cervejeiro, pela técnica de infusão, utilizando apenas malte de cevada. A segunda etapa foi a condução da fermentação através de uma batelada em cortes avaliando-se a produção em etanol, assim como o consumo de carboidratos. De acordo com os resultados, verificou-se que a produtividade volumétrica em etanol da etapa fermentativa após o segundo corte, aumentou $257 \%$ em relação a fermentação conduzida antes do primeiro corte.
\end{abstract}

\section{INTRODUÇÃO}

Segundo Mega et al. (2011), a produção de cerveja é um processo biotecnológico antigo que começou há pelo menos 6.000 anos. Nas últimas décadas do século 19, o processo produtivo evoluiu consideravelmente, devido ao avanço tecnológico, permitindo a produção de cervejas cada vez melhores. Entretanto, as etapas de produção e as operações unitárias inerentes ao processo não mudaram desde então.

Os trabalhos de Rebello (2009) e Schimidell et al. (2001) mencionam que a fermentação alcóolica é a etapa mais demorada de todo processo, juntamente com a maturação pode levar de 4 a 12 semanas e pode ser conduzida de diversas formas, sendo a fermentação descontínua ou batelada tradicional, o método mais usado na produção da 


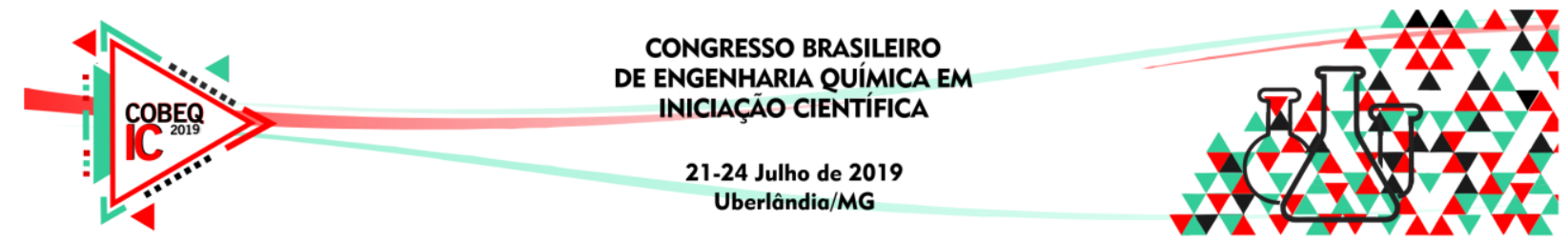

bebida. apesar desse processo possuir baixo custo, devido a sua operação mais simples e baixo risco de contaminação, ele pode reduzir o rendimento e a produtividade devido a inibição por substrato e produto.

Ainda segundo Schimidell et al. (2001), uma alternativa para contornar esse problema é o processo em batelada semicontínuo que é realizado em três etapas. A primeira, ocorre exatamente como na batelada tradicional, inoculando o mosto a ser fermentado com a levedura selecionada. Ao final da fermentação, realiza-se a segunda etapa que consiste em retirar uma fração de mosto fermentado do reator. E por fim, na terceira etapa, ocorre o reabastecimento do fermentador com mosto novo, não fermentado. O produto que não foi retira do fermentador servirá de inóculo para o mosto novo.

\section{METODOLOGIA}

Para a avaliação da fermentação conduzida pelo método semicontínuo, preparou-se 1 litro de cerveja puro malte do estilo American Lager de acordo com as etapas mostradas no Diagrama 1 e utilizando as matérias primas mostradas na tabela 1.

Diagrama 1 - Metodologia para o preparo da cerveja

Definição da receita Brassagem Fermentação Análise dos resultados

A brassagem é o processo responsável pelo preparo do mosto, ela pode ser realizada de diversas formas a depender dos equipamentos disponíveis. Para o presente trabalho, realizouse as etapas representadas no diagrama 2.

Diagrama 2 - Metodologia para o preparo do mosto cervejeiro

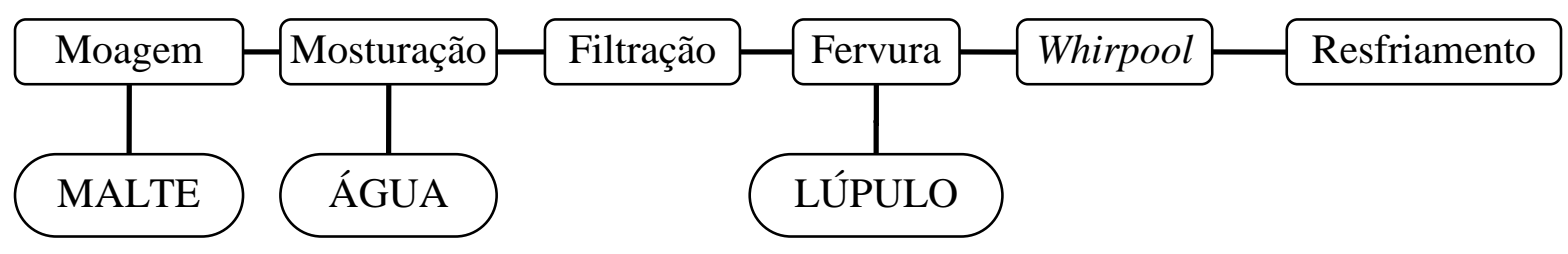




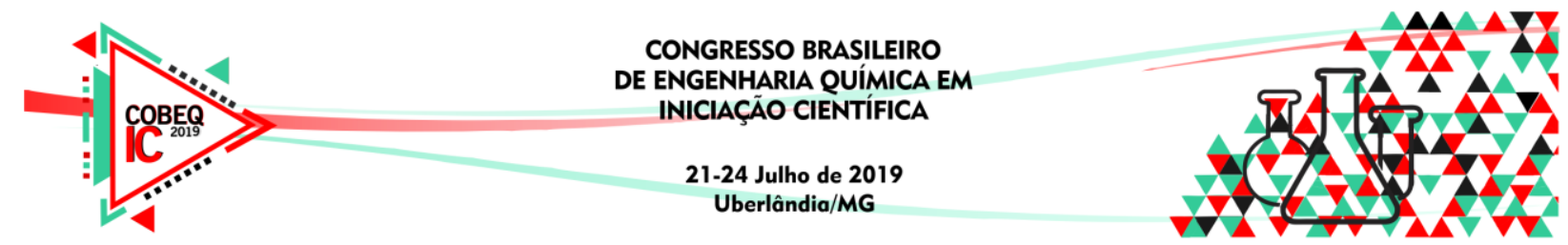

Para o preparo do mosto utilizou-se os insumos mostrados na Tabela 1.

Tabela 1 - Insumos utilizados no preparo do mosto cervejeiro

\begin{tabular}{|c|c|}
\hline Matéria-prima & Quantidade (kg) \\
\hline Malte Pale Ale & 2 \\
\hline $\begin{array}{c}\text { Lúpulo Northern } \\
\text { Brewer }\end{array}$ & 0,0082 \\
\hline Lúpulo Saaz & 0,0055 \\
\hline
\end{tabular}

A moagem dos grãos foi realizada com moedor de grãos no formato de disco da marca Guzzo. Para a mosturação, utilizou-se uma panela de alumínio com capacidade para 15 litros, onde colocou-se todo o malte dentro de uma bolsa de tecido em infusão utilizando-se 6 litros de água destilada, técnica conhecida como brew in a bag (BIAB), como mostrado na figura 5. Com o auxílio de um fogareiro de alta pressão, realizou-se as rampas mostradas na tabela 2.

Figura 2 - Tecido utilizado na técnica brew in a bag.

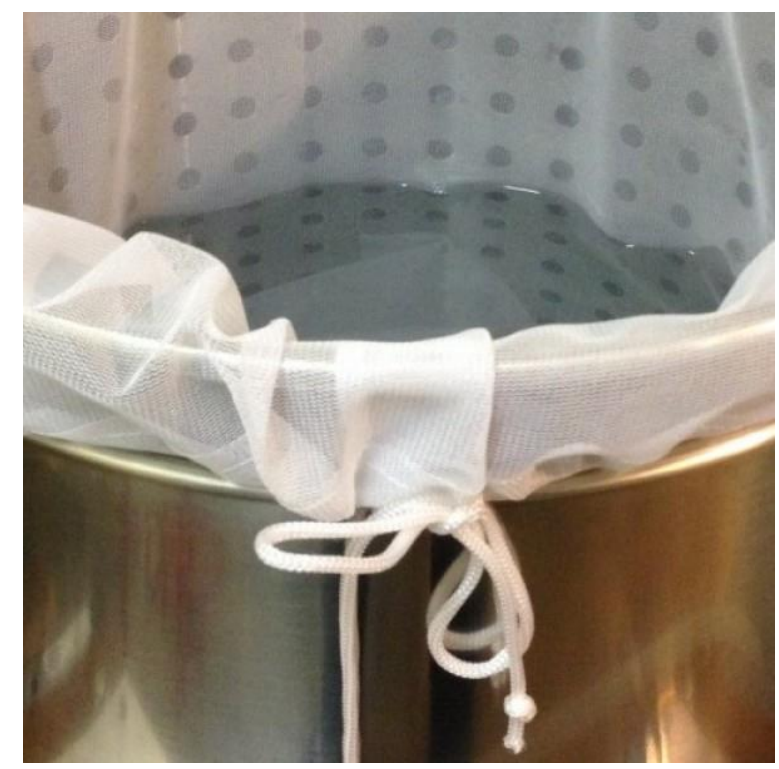




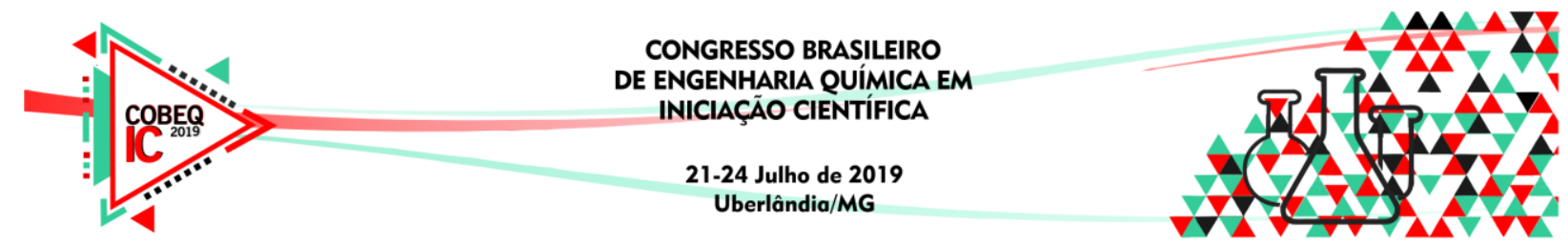

Tabela 2 - Temperaturas usadas na etapa de mosturação e seus respectivos tempos de duração

\begin{tabular}{|c|c|}
\hline $\begin{array}{c}\text { Temperatura } \\
\left({ }^{\circ} \mathbf{C}\right)\end{array}$ & $\begin{array}{c}\text { Tempo } \\
\text { (minutos) }\end{array}$ \\
\hline 62 & 90 \\
\hline 72 & 10 \\
\hline 78 & 5 \\
\hline
\end{tabular}

Antes da rampa de inativação das enzimas $\left(78{ }^{\circ} \mathrm{C}\right.$ por 5 minutos $)$, realizou-se o teste do iodo para verificar a conversão completa do amido. Em seguida, o cereal foi removido do mosto e aguardou-se a drenagem do líquido. Ao final desta etapa, obteve-se 4 litros de mosto primário com densidade 19,8 graus Plato $\left({ }^{\circ} \mathrm{P}\right)$. Este mosto foi diluído com 3,5 litros de água destilada, obtendo-se 7,5 litros de mosto com densidade $10,9^{\circ} \mathrm{P}$ antes do início da fervura.

A fervura foi realizada por 60 minutos, após 20 minutos do início, adicionou-se o lúpulo Northern Brewer, faltando 10 minutos para terminar esta etapa, adicionou-se o coagulante Whirfloc, próprio para bebidas e exatamente no término da fervura, adicionou-se o lúpulo Saaz. Ao final desta etapa, obteve-se 3,5 litros de mosto com densidade $17^{\circ} \mathrm{P}$ que foi armazenado em geladeira. Para o início da fermentação, dilui-se o mosto concentrado para se obter uma concentração em extrato de $12^{\circ} \mathrm{P}$.

As fermentações foram conduzidas a $12^{\circ} \mathrm{C}$ no biorreator modelo BIO-TEC-PRO da marca Tecnal e utilizou-se a levedura de cepa W-34/70 da marca Fermentis, própria para cerveja de baixa fermentação. E para a medição de etanol utilizou-se o densímetro portátil modelo EasyDens da marca Anton Paar. O volume de cerveja retirada em todos os cortes, foi definido com o auxílio da ferramenta "diluição de mosto" disponível no software Beersmith. Essa quantidade foi tal que, quando adicionado mosto não fermentado com concentração de extrato igual $17^{\circ} \mathrm{P}$, a concentração de extrato no interior do vaso de reação alcançasse, novamente, os $12^{\circ} \mathrm{P}$ do início da fermentação.

\section{RESULTADOS E DISCUSSÕES}

O gráfico apresentado na Figura 3 mostra que a primeira etapa do método fermentativo pesquisado neste trabalho não apresentou consumo do extrato disponível no mosto nas primeiras 48 horas de processo, uma vez que o extrato original permaneceu constante a $12^{\circ} \mathrm{P}$ em duas medições consecutivas. Esse comportamento era esperado, uma vez que esse início é semelhante ao método tradicional de fermentação por batelada descontínua. 


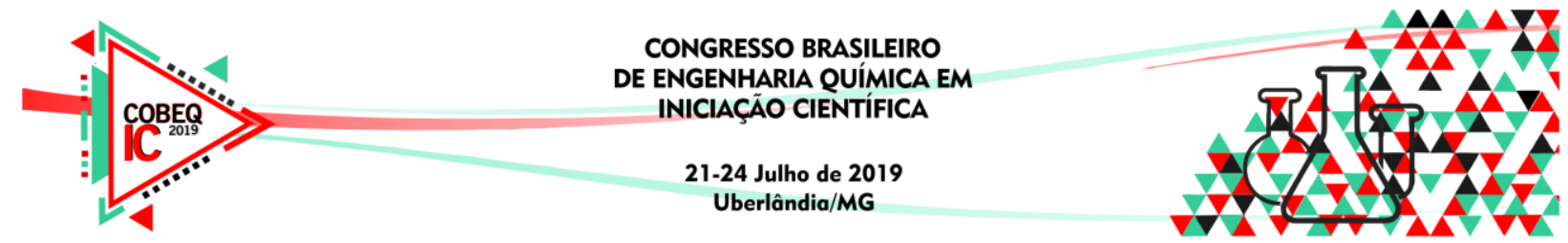

Figura 3 - Comportamento do consumo de extrato do mosto durante a fermentação semicontínua na produção de cerveja a partir de um mosto de malte de cevada.

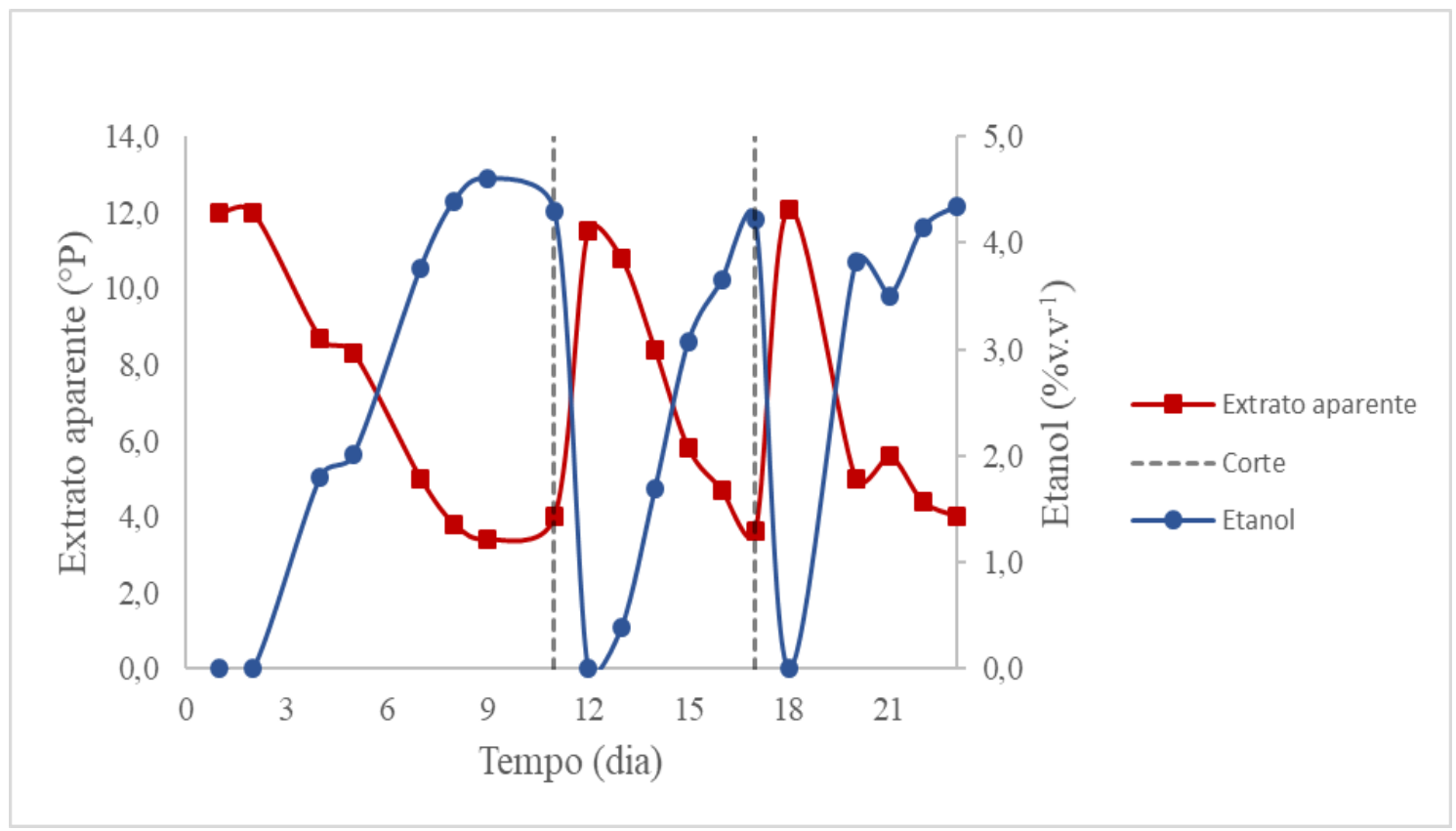

A partir do segundo dia de fermentação, o consumo de extrato se mostrou mais evidente e a fermentação se estabilizou em uma concentração de extrato igual a $4,0^{\circ} \mathrm{P}$. Gerando uma atenuação de aproximadamente $66,6 \%$ do extrato disponível no mosto, produzindo uma cerveja com teor alcoólico de aproximadamente 4,3\% (\% v. $\left.\mathrm{v}^{-1}\right)$. Esta etapa durou 10 dias e gerou uma produtividade volumétrica em etanol de $0,14 \mathrm{~g} \cdot \mathrm{L}^{-1} \cdot \mathrm{h}^{-1}$.

A segunda etapa fermentativa iniciou-se após o primeiro corte e alcançou uma atenuação de $68,7 \%$ do extrato disponível em apenas 5 dias, metade do tempo necessário para obter o mesmo resultado na primeira fermentação. Após o primeiro corte, o processo gerou uma cerveja com aproximadamente $4,2 \%$ de etanol $\left(\% \mathrm{v} \cdot \mathrm{v}^{-1}\right)$ e atingiu uma produtividade volumétrica em etanol de $0,28 \mathrm{~g} \cdot \mathrm{L}^{-1} \cdot \mathrm{h}^{-1}$, o dobro da produtividade alcançada na primeira etapa.

Após o segundo corte, iniciou-se a terceira fermentação e nas primeiras 24 horas alcançou-se uma atenuação de $58 \%$ do extrato disponível. Toda etapa durou 4 dias, produzindo uma cerveja com aproximadamente $4,4 \%$ de etanol $\left(\%{\mathrm{v} . \mathrm{v}^{-1}}^{-1}\right)$ e gerando uma produtividade volumétrica em etanol de $0,36 \mathrm{~g} \cdot \mathrm{L}^{-1} \cdot \mathrm{h}^{-1}$. Um aumento de $257 \%$ quando comparado com a produtividade obtida na primeira fermentação (Figura 4). 


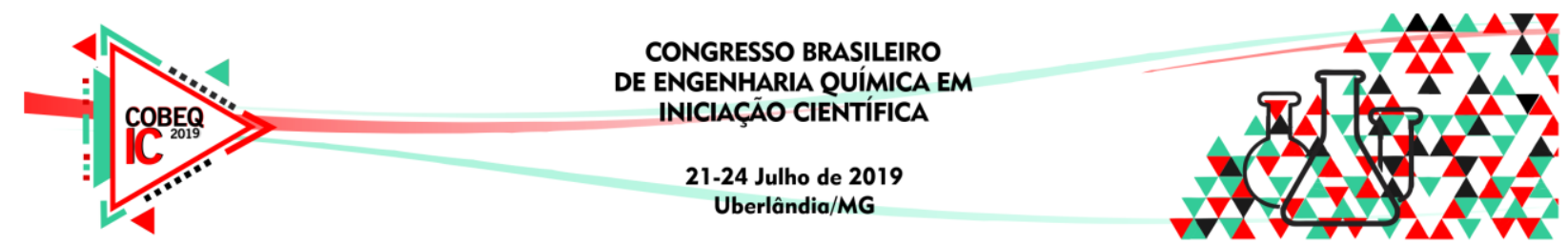

Figura 4 - Produtividade volumétrica em etanol em diferentes etapas da fermentação semicontínua para produção de cerveja a partir de um mosto de malte de cevada.

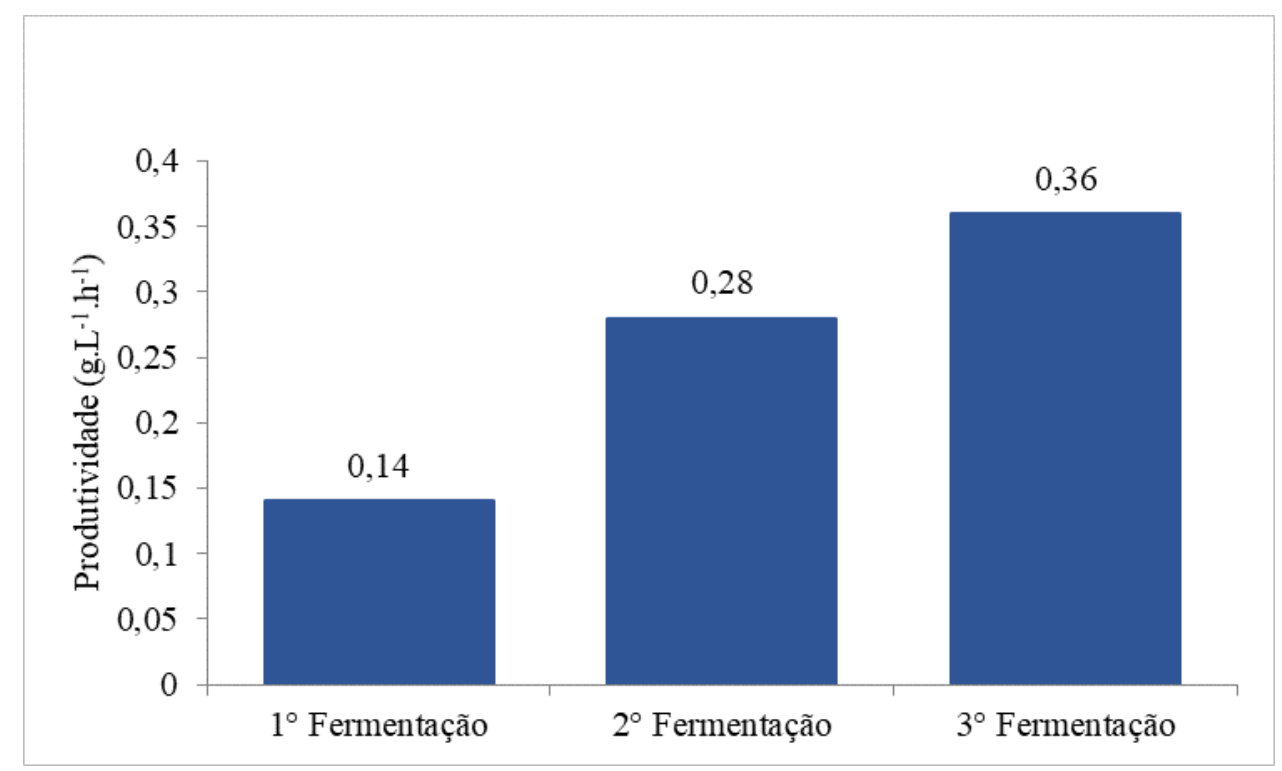

\section{CONCLUSÃO}

Conclui-se que os primeiros cortes realizados na fermentação semicontínua na produção de cerveja permite obter expressivos ganhos na produtividade volumétrica em etanol. O próximo passo do trabalho é avaliar o limite de cortes possíveis sem afetar a produtividade em etanol.

\section{REFERÊNCIAS}

MEGA, J. F.; NEVES, E.; ANDRADE, C. J.; A produção de cerveja no Brasil. Revista CITINO., v. 01, p. 34-42, 2011.

SCHIMIDELL, W.; LIMA, U. A.; AQUARONE, E.; BORZANI, W.; Biotecnologia industrial. São Paulo: Editora Blucher, 2001.

REBELLO, F. F. P.; Produção de cerveja. Revista Agroambiental., p.145-155, 2009. 